\title{
O ensino de Desenho na década de 1920: O que tratam as Revistas de Educação da Bahia?
}

Emanuel Silva Santos

Claudinei de Camaro Sant' Ana

\section{Resumo}

Neste artigo, investigamos acerca do ensino de Desenho na década de 1920, especificamente nos valemos de exemplares da "Revista de Educação-Orgam da Escola Normal de Caetité", periódico que foi catalogado pelo Grupo de Estudos em Educação Matemática (GEEM) ${ }^{36}$. Analisamos as publicações veiculadas em 1927 e 1928, em particular dos meses de fevereiro, junho e agosto. Este artigo apresenta sustentação teórica na História das Disciplinas Escolares, Chervel (1990) e na Cultura Escolar, Dominique Julia (2001). A investigação nos revelou vestígios de como transcorreu o ensino de Desenho no contexto educacional da Bahia na década de 1920 e a sua provável relação com a Ambidextria, Anatomia humana e Saberes Elementares Matemáticos. Assim, esperamos que o nosso trabalho possa corroborar no seguinte entendimento: Qual foi a relação entre o ensino de Desenho e a Matemática na década de 1920 no Estado da Bahia?

Palavras-chave: Disciplinas Escolares. Educação Matemática. Cultura Escolar. Ensino do Desenho. 


\title{
The teaching of Drawing in the decade of 1920: What does the Education Magazine of Bahia treat?
}

\author{
Emanuel Silva Santos \\ Claudinei de Camargo Sant' Ana
}

\begin{abstract}
In this article, we investigated the teaching of Design in the 1920s, specifically we use copies of the "Journal of Education-Orgam Normal School of Caetité", a journal that was cataloged by the Group of Studies in Mathematics Education (GEEM). We analyze the publications published in 1927 and 1928, in particular the months of February, June and August. This article presents theoretical support in the History of School Disciplines, Chervel (1990) and in School Culture, Dominique Julia (2001). The research revealed traces of how the teaching of Drawing in Bahia's educational context occurred in the 1920 s and its probable relationship with Ambidextria, Human Anatomy, and Elementary Mathematical Knowledge. Thus, we hope that our work can corroborate in the following understanding: What was the relation between the teaching of Drawing and Mathematics in the 1920 s in the State of Bahia?
\end{abstract}

Keywords: School Disciplines. Mathematical Education. School Culture. Teaching the Drawing. 


\section{Introdução}

Seguindo com a proposta de investigação historiográfica ${ }^{37}$ e analisando as indicações para o ensino do Desenho nos periódicos educacionais, a presente pesquisa se estreita na pretensão de investigar: "Qual foi a relação entre o ensino de Desenho e a Matemática na década de 1920 no Estado da Bahia?”. Para tal aspiração, utilizamos nesse primeiro momento, algumas "Revistas de Educação-Orgam da Escola Normal de Caetité" ${ }^{38}$, que foram publicadas no município de Caetité-BA39 e que foram catalogadas pelo GEEM40.

Assim, visando seguir essa proposição de investigação historiográfica concordamos com Cerri (2009), quando argumentou que:

[...] podemos definir uma concepção historiográfica como uma vertente teórica e metodológica de um corpo formalizado de estudos - a História - e, portanto, um fenômeno disciplinar. A concepção historiográfica se identifica, então, como um fenômeno inerente a uma forma específica de conhecimento, quer o chamemos de ciência, disciplina, arte, saber. O fato é que se trata de uma forma de conhecimento institucionalizada e profissionalizada (ainda que no Brasil não esteja ainda regulamentada a profissão de historiador), originada na Europa do século XIX e daí difundida a quase todo o mundo. [...] (CERRI, 2009, p. 1).

Nessa passagem Cerri (2009) pontuou a distinção entre a historiografia e história, sendo a primeira definida como um fenômeno inerente a uma forma específica de conhecimento, enquanto história refere-se a um fenômeno social que pode estabelecer sentidos para o tempo experienciado pela coletividade.

Coadunando com esse entendimento e por considerarmos que a História das Disciplinas Escolares é um fator preponderante para nossa pesquisa, trazemos Chervel (1990), quando teorizou:

A história das disciplinas escolares não deve, entretanto ser considerada como uma parte negligenciada da história do ensino que, depois de corrigida, viria a lhe acrescentar alguns capítulos. Pois não se trata somente de preencher

\footnotetext{
37 Para o trabalho do historiador, é fundamental a distinção entre historiografia (narratio rerum gestarum) e história (resgestae), a primeira designando o conhecimento histórico produzido pelo historiador e a segunda referindo-se aos conhecimentos, sujeitos e processos, dentre outros, que constituem o objeto do conhecimento histórico (DIAS,2012,p.1).Instituto de Humanidades Artes e Ciências, UFBA-. Educ. Matem. Pesq, São Paulo, v.14, n 3, p.301$321,2012$.

${ }^{38}$ Direitos autorais de: Typ. d' A PENNA - Gumes \&Filhos.

39Distante 645 quilômetros da capital do estado, Salvador e, segundo a estimativa de população 2015 tem, aproximadamente, 52.531 habitantes. Com mais de dois séculos de emancipação, a cidade foi polo cultural da região sertaneja da Bahia: foi a terra natal de figuras como: Anísio Teixeira. Foi, ainda, pioneira na educação regional, com a primeira escola normal do sertão baiano. Disponível em: http://www.caetite.ba.gov.br/a-historia/. Acesso em $26 / 12 / 2017$.

40Fundado em 2004, o Grupo de Estudos em Educação Matemática - GEEM possui como foco de investigação as seguintes linhas de pesquisa: Formação de Professores, História do Ensino de Matemática, Tecnologias de Informação e Comunicação no Ensino. Disponível em http://2015.geem.galoa.com.br/br/node/1059. Acesso em $30 / 05 / 2017$.
} 
uma lacuna na pesquisa. O que está em questão aqui é a própria concepção da história do ensino [...] (CHERVEL, 1990, p. 183).

Salientamos que algumas dessas Revistas de Educação, estão disponíveis no Repositório Institucional (RI) da Universidade Federal de Santa Catarina (UFSC) ${ }^{41}$, que atualmente disponibiliza $94.688^{42}$ arquivos para consulta e outros documentos foram catalogadas e disponibilizadas pelo Grupo de Estudos em Educação Matemática (GEEM) ${ }^{43}$ também em seu site ${ }^{44}$, na linha de pesquisa em História da Educação45.

A pesquisa está vinculada à investigação atual que o grupo desenvolve ${ }^{46}$, existem outras pesquisas que também exploraram os periódicos pedagógicos que circularam pela Bahia, por exemplo: Sant'Ana, Santana, Amaral (2015) e Sant'Ana, Santana (2015), onde são apresentadas as ações para obtenção e digitalização das fontes que em muito favoreceu o desenvolvimento de outras pesquisas.

Quanto a História da Educação Matemática, o Repositório Institucional da Universidade Federal de Santa Catarina (UFSC) representa uma importante "ferramenta" de investigação, pois reúne as condições necessárias para as pesquisas de cunho históricocomparativa, onde o GEEM está inserido, denominado de: “A Constituição dos Saberes Elementares Matemáticos: a Aritmética, a Geometria e o Desenho no curso primário em perspectiva histórico-comparativa, 1890-1970".

Para o desenvolvimento e aprofundamento da nossa pesquisa, buscamos organizar as fontes disponíveis, catalogação de Revistas Pedagógicas publicadas no Estado da Bahia, análise das leis e decretos.

Dessa forma acreditamos que essa linha de raciocínio proporcionou uma interação entre teoria e problema de pesquisa. Por fim, a partir dessas premissas, elencamos no quadro (1), as publicações catalogadas que serão analisadas neste trabalho.

\footnotetext{
${ }^{41} \mathrm{O}$ Repositório Institucional (RI) da Universidade Federal de Santa Catarina (UFSC) tem como missão armazenar, preservar, divulgar e oferecer acesso a produção científica e institucional da UFSC. Possui como objetivos: contribuir para o aumento da visibilidade dos pesquisadores e da produção científica da UFSC; preservar a memória intelectual da Universidade; reunir em um único local virtual e de forma permanente a produção científica e institucional, disponibilizando o livre acesso aos conteúdos digitais e ampliar e facilitar o acesso à produção científica de uma forma geral. Manuais, vídeos-tutoriais e outras informações sobre o RI podem ser encontradas em: http://www.repositorio.ufsc.br.

${ }^{42}$ Esses valores podem variar de acordo com a data pesquisada.

43Site do grupo: http://geem.mat.br.Acesso em 30/06/2017.

44Acervo digital: http://geem.mat.br/br/node/81. Acesso em 30/05/2017.

${ }^{45}$ São integrantes nesta linha de pesquisa: Claudinei de Camargo Sant 'Ana; Irani Parolin Sant 'Ana; Rosemeire dos Santos Amaral; Tatiana Silva Santos Soeres; Márcio Oliveira D’ Esquivel e Emanuel Silva Santos e Fabricia Peixoto.

${ }^{46} \mathrm{O}$ Ensino de Matemática no Curso Primário no Estado da Bahia: a caracterização de um percurso. ISSN 2526-2882 
Quadro 1:Revistas de Educação Catalogadas

\begin{tabular}{|l|l|}
\hline \multicolumn{1}{|c|}{$\begin{array}{c}\text { Nome da Revista/ Mês /Ano de } \\
\text { Publicação }\end{array}$} & \multicolumn{1}{c|}{ Artigos relevantes/ Autor (es) } \\
\hline $\begin{array}{l}\text { Revista de Educação - Orgam da escola normal } \\
\text { de Caitete'47. Anno I / junho de 1927 }\end{array}$ & Ambidextria/Não há registros \\
\hline $\begin{array}{l}\text { Revista de Educação - Orgam da escola normal } \\
\text { de Caitete'48. Anno I /agosto de 1927. }\end{array}$ & $\begin{array}{l}\text { O Segredo do Desenho/Maria Constança P } \\
\text { Cardoso. }\end{array}$ \\
\hline $\begin{array}{l}\text { Revista de Educação- Orgam da escola normal } \\
\text { de Caitete49.Anno II/Fevereiro de 1928. }\end{array}$ & $\begin{array}{l}\text { O Ensino do Desenho na Escola Primária/Não } \\
\text { há registros. }\end{array}$ \\
\hline
\end{tabular}

Fonte: Elaborado a partir das catalogações

Por conseguinte, para colaborar no entendimento do problema de pesquisa aqui construído, consideramos relevante discorrer sobre a instrução pública que se estabeleceu na Bahia na década supracitada.

\section{Programa do ensino da escola elementar urbana}

Quase seis meses antes da reforma da Instrução Pública do Estado da Bahia (Lei ${ }^{\circ}$ 1846), Anísio Teixeira apresentou em 18 de março de 1925, o Programa do ensino da Escola Elementar urbana ${ }^{50}$ do Estado da Bahia. Informou que:

Foram esses programmas das escolas primarias elementares organizados pela comissão do Conselho Superior do Ensino composta Drs. Alfredo Ferreira de Magalhães, Isaias Alves de Almeida e D. Maria Luiza de Souza Alves [...]. O Conselho Superior do Ensino [...], approvou e adoptou os novos programmas, que o Inspector Geral do Ensino resolve distribuir, desde já, às escolas publicas elementares (BAHIA, Imprensa Oficial, 1925, p.36).

Segundo Luz (2013), essa atitude de antecipação de Anísio Teixeira era:

[...] uma estratégia administrativa, pois esperar a reforma poderia significar perder mais um ano letivo sem implantar os novos programas, já que a reforma era esperada para o final de 1924 e só seria colocada em prática no início de 1926. Era preciso substituir os planos de estudos de 1920 e colocar em prática o que ainda não existia, ou seja, programas para o curso primário (LUZ, 2013, p.135).

O programa do ensino da Escola Elementar Urbana deliberou sobre as matérias escolares (quadro 2), o que deveriam ser ministradas no $1^{\circ}$ ao $4^{\circ}$ Ano do Ensino Elementar, a saber:

${ }^{47} \mathrm{Grafia}$ da época.

${ }^{48}$ Idem.

49Idem.

50 Publicado em 18 de março de 1925. 
Quadro 2: Programas de Ensino da Escola Elementar

\begin{tabular}{|c|c|}
\hline 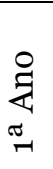 & $\begin{array}{l}\text { Língua Vernácula; Caligrafia; Aritmética; Geometria; Geografia; História do Brasil; Elementos } \\
\text { de Ciências Físicas e Naturais, Noções de Higiene; Desenho; Trabalhos Manuais; Prendas; } \\
\text { Educação Moral e Cívica; Canto e Música; Educação Física. }\end{array}$ \\
\hline $\begin{array}{l}\text { 妾 } \\
\text { i } \\
\text { N }\end{array}$ & $\begin{array}{l}\text { Língua Vernácula; Caligrafia; Aritmética; Geometria; Geografia; História do Brasil; Elementos } \\
\text { de Ciências Físicas e Naturais, Noções de Higiene; Desenho; Trabalhos Manuais; Prendas; } \\
\text { Canto e Música. }\end{array}$ \\
\hline $\begin{array}{l}\stackrel{1}{4} \\
\text { on }\end{array}$ & $\begin{array}{l}\text { Língua Vernácula; Caligrafia; Aritmética; Geometria; Geografia; História do Brasil; Elementos } \\
\text { de Ciências Físicas e Naturais, Noções de Higiene; Desenho; Trabalhos Manuais; Prendas; } \\
\text { Educação Moral e Cívica; Canto e Música. }\end{array}$ \\
\hline 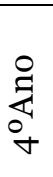 & $\begin{array}{l}\text { Língua Vernácula; Caligrafia; Aritmética; Geometria; Geografia; História do Brasil; Elementos } \\
\text { de Ciências Físicas e Naturais, Noções de Higiene; Desenho; Trabalhos Manuais; Prendas; } \\
\text { Educação Moral e Cívica; Canto e Música. }\end{array}$ \\
\hline
\end{tabular}

Fonte: BAHIA, Imprensa Oficial, 1925, p. 36

O ensino do Desenho e dos Trabalhos Manuais deveria ser educativo, buscando desenvolver nas crianças o sentido da sua personalidade, dando condições para transformar seu pensamento em ação, passando suas ideias e pensamentos para representação material. Desse modo:

O esforço natural do alunno deve ser estimulado de sorte que lhe dê o gosto e o prazer da difficuldade a vencer. [...]. Nada deve ser convencional ou copiado. O professor será apenas o guia da actividade dos alumnos, convidando-os á observação da realidade, sobretudo das suas proporções (Bahia, Imprensa oficial, 1925, p. 36).

Somado a isso, o ensino do Desenho e dos Trabalhos Manuais, precisariam ser orientados em torno dos "Centros de Interesses" ${ }^{51}$. Corroborando com essas indicações, o programa do ensino da Escola Elementar urbana recomendou que ensino do Desenho para o $1^{\mathrm{o}}$ ano Primário, deveria ser orientado a partir do "Desenho a mão livre, de memória e de imaginação, Plantas e Paysagens, Recórte da silhueta das arvores, Estudo gráfico das siluetas, coloração a lapis” (BAHIA, Imprensa oficial, 1925, p.36).

\footnotetext{
${ }^{51}$ Os centros de interesses são um processo de ensino que consiste em agrupar à volta dum mesmo assunto que interessa à criança um conjunto de noções a aprender, de mecanismos a montar, de hábitos a adquirir, [...](BASSAN ,1978, p. 17). Essa estratégia foi criada pelo médico belga Ovide (Ovídio) Decroly, conhecido pelos seus estudos sobre a psicologia infantil, principalmente sobre o desenvolvimento da criança e a preservação da sua liberdade. A base psicológica desta estratégia reside em considerar a vida mental do indivíduo como unidade; portanto, os temas ou conteúdos a serem estudados devem ser apresentados no seu todo e não repartidos em disciplinas ou áreas do conhecimento (CINEL, 2004, p.33).
} 
Para o $2^{\circ}$ ano Primário, as recomendações eram demarcadas em torno de "Animaes Recórte no papel. O animal d'après nature ${ }^{2}$. $\mathrm{O}$ animal na paysagem. Desenho de fórmas geométricas e dos objectos derivados dessas fórmas" (BAHIA, Imprensa oficial, 1925, p.36).

Em relação ao $3^{\circ}$ ano Primário, as recomendações foram: Desenho da figura humana, estudo da silueta, aplicação de cores e tons, Desenho decorativo ou ornamental, exercícios sobre a fauna e flora brasileira. Suas aplicações para a ornamentação do lar. Em se tratando do $4^{0}$ ano primário, o programa, advertiu que seria baseada na "Repetição geral. Exercicios geraes sobre qualquer assumpto dos programmas anteriores" (BAHIA, Imprensa oficial, 1925, p. 36).

\section{A instrução pública baiana}

$\mathrm{Na}$ abertura da $2^{\mathrm{a}}$ reunião ordinária da $18^{\mathrm{a}}$ legislatura, o governador Dr. Francisco Marques de Góes Calmon53, em sete (7) de abril de 1926, apresentou a Assembleia Geral Legislativa, os principais pontos sobre a administração do Estado em particular sobre a instrução pública, ponderou que o ensino público ano de 1925 seria para Bahia "lento mais seguro resurgimento" (BAHIA, Mensagem... 1926, p.34), garantiu sua restauração através de medidas empreendidas pelo seu governo e que para isso seria necessário uma reforma nas suas próprias leis.

Nesse período, o diretor geral da instrução pública, Anísio Spinola Teixeira se destacou pelo seu empenho a favor da regulamentação da Lei no 184654 de 14 de agosto de 1925 e o Decreto $\mathrm{n}^{0} 4312^{55}$ de 30 de dezembro de 1925. Desse modo, em dezembro do mesmo ano, o governo da Bahia publicou o regulamento do ensino primário e no ano de 1926 se iniciou com a entrada em execução da reforma legislativa do serviço baiano de ensino. $O$ fato dessa reforma não ter sido aplicado no ano corrente (1925), se justificou porque o projeto de reforma do ensino foi transformado em lei, apenas no meio do período letivo, "um pouco depois do primeiro semestre do anno findo" (BAHIA, Mensagem..., 1926, p.34) assim, o governo foi obrigado a aplicá-lo no próximo ano (1926), pois seria início do novo ano escolar.

Góes Calmon (1926) argumentou sobre a especificidade do ensino popular56, afirmou que "era exclusivamente urbano, com o curso, chamado complementar, afastado de

\footnotetext{
$5^{2}$ Obra de arte realizada diretamente a partir da natureza.

53Francisco Marques de Góes Calmon, banqueiro, advogado e ex-governador da Bahia, nasceu em Salvador, no dia 6 de novembro de 1874, sendo seus pais o almirante e chefe político Antônio Calmon Du Pin e Almeida e Maria dos Prazeres da Cunha Góes [...] Em 1894, concluiu o curso de direito. No ano seguinte iniciou a vida profissional em Salvador, no escritório de advocacia de seu tio e pai adotivo. No mesmo ano foi nomeado professor substituto de Cronografia e História do Brasil, no Ginásio da Bahia, primeiro e único estabelecimento de ensino secundário até então existente na Bahia [...] Faleceu relativamente jovem, em 29 de janeiro de 1932 com, apenas, 58 anos de idade. Disponível em: http://ilustresdabahia.blogspot.com.br/2014/02/157-francisco-marques-. Acesso em 25/o5/2017. 54Refere-se à lei que reforma a instrução pública da Bahia em 14 de agosto de 1925.

55Refere-se ao decreto que aprova o Regulamento do ensino primário e normal em 1925.

${ }^{56}$ Trata-se de uma escola urbana, com função meramente literária, direcionada para o povo.
} ISSN 2526-2882 
qualquer cogitação technica ou profissional, dando á nossa escola primaria a feição meramente literária [...]" (BAHIA, Mensagem...,1926, p.34).

O governo calmonista desejava instituir uma reorganização da instrução pública no ensino primário baiano, por considerar a que mesma era defeituosa, imprecisa, mecanizada e privada de características essências para sua eficiência, necessitando assim de uma urgência em um plano, método e programa que uniformizasse o ensino primário da Bahia.

As mudanças pretendidas pelo governo de Góes Calmon alcançaram também a formação do baiano quando sinalizou que seria baseada na escola elementar57 urbana e rural, sendo continuada quando possível pela escola primária superior ${ }^{8}$, a qual tinha como atribuição a aliança entre a cultura geral, cultura técnica e cultura profissional.

Uma das modificações empreendidas pela Lei $n^{0} .1846$, de 14 de agosto de 1925 , referiu-se à unificação do ensino ${ }^{59}$ sob o controle do Estado. Dessa forma, em 18 de dezembro do referido ano, o diretor da Instrução Pública (Anísio Teixeira), emitiu uma extensa carta a todos os intendentes do Estado, o qual explanou sobre as causas necessárias para centralização do serviço escolar estadual, ressalvando que a referida reforma se dava "um sentido uniforme e adaptado ás condições de nossa terra, bem como organização técnica, retirou dos municípios a imediata administração do ensino, para confiá-la ao Estado" (BAHIA, Mensagem..., 1926, p.44).

A colaboração pretendida por Anísio Teixeira, para unificação do serviço escolar estadual e municipal, contava com o apoio irrestrito dos municípios através dos seus intendentes "E’necessario collaboreis na mais estreita harmonia com esta Directoria, afim de que a transferência do serviço escolar municipal para o Estado, se effective dentro nos planos da lei [...]” (Bahia, mensagem..., 1926, p.45).

Prevendo isso, cria o conselho escolar do município o qual deveria "exprimir com efficiencia essa collaboração que desejamos enthusiastica e a que o Governo dará sempre um acolhimento, em especial benevolente" (Bahia, mensagem..., 1926, p.45).

O Estado buscou o controle sobre a instrução pública, cobrou a participação e harmonia dos representantes municipais, afim de que segundo Anísio, alcançaria o expressivo melhoramento do serviço escolar baiano.

\footnotetext{
57Segundo Zotti (2006), [...] escola considerada a base sobre a qual se erguem os demais graus de ensino que constituem a estrutura da educação escolarizada.

${ }^{58}$ Trata-se de um tipo de escola primária e tem por objetivo o desenvolvimento da educação ministrada na escola elementar e provimento de instrução especial para as futuras ocupações dos estudantes.

59Refere-se à unificação do serviço escolar estadual e municipal, proclamada pela Lei 1846 de 14 de agosto de 1925 no estado da Bahia.
} 
Para que o acordo fosse efetivado, seria necessário que o município de Salvador, transferisse o serviço do ensino o qual passaria a ser superintendido, dirigido e fiscalizado pelo Governo do Estado.

Quanto ao serviço do ensino, o mesmo era compreendido pelas "as escolas elementares primarias creadas por leis municipaes em numero de cento e setenta (170), inclusive as do Grupo Escolar, além de seis (6) escolas noturnas” (BAHIA, Mensagem..., 1926, p.47).

Em se tratando dos professores, os mesmos seriam transferidos para jurisdição estadual, mantendo-se os seus direitos anteriormente adquiridos. As nomeações, remoções, permutas e acessos de professores municipais nas escolas transferidas, deveriam seguir a lei estadual, como também questões relativas à aposentadoria, essas custeadas pelo Governo do Estado.

As mais diversas condições foram requeridas pelo Governo do Estado para superintender a unificação do serviço de ensino. Versavam sobre as contribuições para o Monte-Pio ${ }^{60}$, as quais deveriam ser deduzidas dos vencimentos dos professores pelo tesouro do Estado; direito de localizar as escolas transferidas de acordo com as necessidades do ensino; receber do município de Salvador as verbas para custear a instrução pública primária e, por conseguinte, o acordo firmado entre o município de Salvador e o governo baiano, deveria ser aprovado mediante consentimento do conselho escolar municipal.

Segundo D’Esquivel; Sant'Ana, (2016), a reforma educacional que ocorreu na Bahia entre 1924 e 1928, possibilitou alavancar uma discussão em torno da ação do aluno como fator preponderante na aquisição da aprendizagem, assim descrito:

A reforma educacional em andamento na Bahia, entre os anos 1924 e 1928, aposta na ação do aluno como fator desencadeador da aprendizagem. Se esta concepção para o ensino já vinha sendo uma tendência educacional desde o final do século XIX, na reforma baiana de 1925, se constitui em diretriz principal que orienta os currículos e programas, determina a escolha de manuais didáticos e publicações pedagógicas e irá inspirar a preparação e o aperfeiçoamento dos professores para a escola de ensino primário. À tendência pedagógica experimentalista de educação, que já era um dos pressupostos do método de ensino intuitivo, novos ramos do conhecimento serão agregados (D’ESQUIVEL; SANT'ANA, 2016, p. 191).

Essa passagem ainda nos confirma que a reforma de $1925^{61}$ que ocorreu na Bahia, tinha como diretriz principal a inclusão do aluno no processo educacional não mas como mero

\footnotetext{
${ }^{60}$ Grafia da época. Instituição em que cada sócio, pagando mensalmente uma quantia, adquire direito como o de subsídio em caso de doença e o de deixar pensão após a morte para sua família. A pensão paga por essa instituição. Disponível em: https://www.dicio.com.br/montepio/. Acesso em 26/12/2017.

${ }^{61}$ Lei no ${ }^{1846}$, de 14 de Agosto de 1925, que tratou sobre a instrução pública do Estado da Bahia. ISSN 2526-2882 
coadjuvante e sim como "mola" mestre, influenciando inclusive na formulação dos currículos, programas e também na escolha dos manuais didáticos, publicações pedagógicas e sem dúvida no aperfeiçoamento dos professores do ensino primário.

É relevante também considerar que no Brasil a partir de 1920 as discussões em torno das reformas educacionais:

[...] ganharam amplitude jamais vista no país, onde estavam, em pleno fervor, de um lado as idéias pedagógicas da Escola Nova, que dava grande valor à psicologia, e de outro, os católicos a favor da manutenção da Pedagogia Tradicional. Apesar de ter nascido nos movimentos da burguesia e da classe média, as propostas de mudanças educacionais da Escola Nova era um grande avanço: propunham 5 "métodos ativos" de ensino aprendizagem, deu importância à liberdade da criança e ao interesse do educando, adotou métodos de trabalho em grupo e incentivou a prática de trabalhos manuais nas escolas, valorizou os estudos de psicologia experimental e procurou colocar a criança, e não mais o professor, no centro do processo educacional.(BERTI,2005, p.4).

Verifica-se nessa passagem a valorização do movimento de renovação do ensino intitulada de "Escola Nova ${ }^{62}$ ", que versava sobre a liberdade das crianças, o interesse dos educandos e a utilização de trabalhos em grupos e/ou manuais, dentre outros. Somado a isso, a criança torna-se o centro do processo educacional e não mais o professor.

Coadunando com essa perspectiva, Bomeny (2003), aludiu que a Escola Nova, direcionava suas orientações em torno da concepção do aprendizado do aluno por si mesmo, por sua capacidade de observação, de experimentação, dentre outros, assim descrito:

A Escola Nova, inspirada em grande medida nos avanços do movimento educacional norte-americano, mas também de outros países europeus, teve grande repercussão no Brasil. Os ideais que lhe deram corpo foram sempre inspirados na concepção de aprendizado do aluno por si mesmo, por sua capacidade de observação, de experimentação, tudo isso orientado e estimulado por profissionais da educação que deveriam ser treinados especialmente para esse fim [...] (BOMENY, 2003, p. 43).

\footnotetext{
62 Escola Nova é um dos nomes dados a um movimento de renovação do ensino que foi especialmente forte na Europa, na América e no Brasil, na primeira metade do século XX. "Escola Ativa" ou "Escola Progressiva" são termos mais apropriados para descrever esse movimento [...]Os primeiros grandes inspiradores da Escola Nova foram o escritor Jean-Jacques Rousseau (1712-1778) e os pedagogos Heinrich Pestalozzi (1746-1827) e Freidrich Fröebel (1782-1852). O grande nome do movimento na América foi o filósofo e pedagogo John Dewey (1859-1952). O psicólogo Edouard Claparède (1873-1940) e o educador Adolphe Ferrière (1879-1960), entre muitos outros, foram os expoentes na Europa.No Brasil, as ideias da Escola Nova foram introduzidas já em 1882 por Rui Barbosa (18491923). No século XX, vários educadores se destacaram, especialmente após a divulgação do Manifesto dos Pioneiros da Educação Nova, de 1932. Podemos mencionar Lourenço Filho (1897-1970) e Anísio Teixeira (1900-1971), Disponível em: http://www.educacional.com.br/glossariopedagogico/verbete.asp?idPubWiki=957. Acesso em 26/12/2017.
} 


\section{As revistas de educação: o ensino do desenho e sua relação com a matemática}

Por que utilizamos as Revistas como fonte histórica? Concordamos com Catani (1996) quando argumentou:

De fato, as revistas especializadas em educação, no Brasil e em outros países, de modo geral, constituem uma instância privilegiada para a apreensão dos modos de funcionamento do campo educacional enquanto fazem circular informações sobre o trabalho pedagógico e o aperfeiçoamento das práticas docentes, o ensino específico das disciplinas, a organização dos sistemas, [...] (CATANI, 1996, p. 115-130).

Assim, por essa ponderação entendemos que para Catani (1996), as revistas especializadas em educação constituem um “instrumento" privilegiado para a apreensão dos modos de funcionamento do campo educacional, pois possibilita a circulação dos trabalhos pedagógicos, das práticas docentes, do ensino específico das disciplinas, da organização dos sistemas, dentre outros.

Contribuindo com essa perspectiva, Bastos (1997) alegou o valor e a relevância da imprensa pedagógica no cotidiano educacional e escolar, permitindo ao pesquisador o estudo do pensamento pedagógico.

a imprensa pedagógica - instrumento privilegiado para a construção do conhecimento, constitui-se em um guia prático do cotidiano educacional e escolar, permitindo ao pesquisador estudar o pensamento pedagógico de um determinado setor ou grupo social, a partir da análise do discurso veiculado e a ressonância dos temas debatidos, dentro e fora do universo escolar. Prescrevendo determinadas práticas, valores e normas de conduta, construindo e elaborando representações do social [...] (BASTOS, 1997, p. 173).

Para D’Esquivel e Sant'Ana (2016), os periódicos educacionais configuram como sínteses dos discursos pedagógicos, tornando-se como uma alternativa de divulgação e dispersão documental sobre um determinado fato histórico.

[...] circulação dos periódicos educacionais em várias províncias do país. Tais publicações constituem como que "sínteses" dos discursos pedagógicos de seu tempo, seja como veículo de reprodução das representações oficiais para a educação, seja como espaço de contestação. Tomados como fontes, os periódicos educacionais são uma alternativa à dispersão documental possível sobre um determinado fato histórico. [...] (D’ESQUIVEL; SANT'ANA, 2016 p.187). 
Em concordância com essas assertivas, iniciamos as nossas discussões com um artigo denominado de "Ambidextria" ${ }_{3}$ publicado na Revista de Educação (figura 1) - Orgam da Escola Normal de Caetité, ano I, Junho de 1927.

Figura 1: Capa da revista de Educação-Junho de 1927

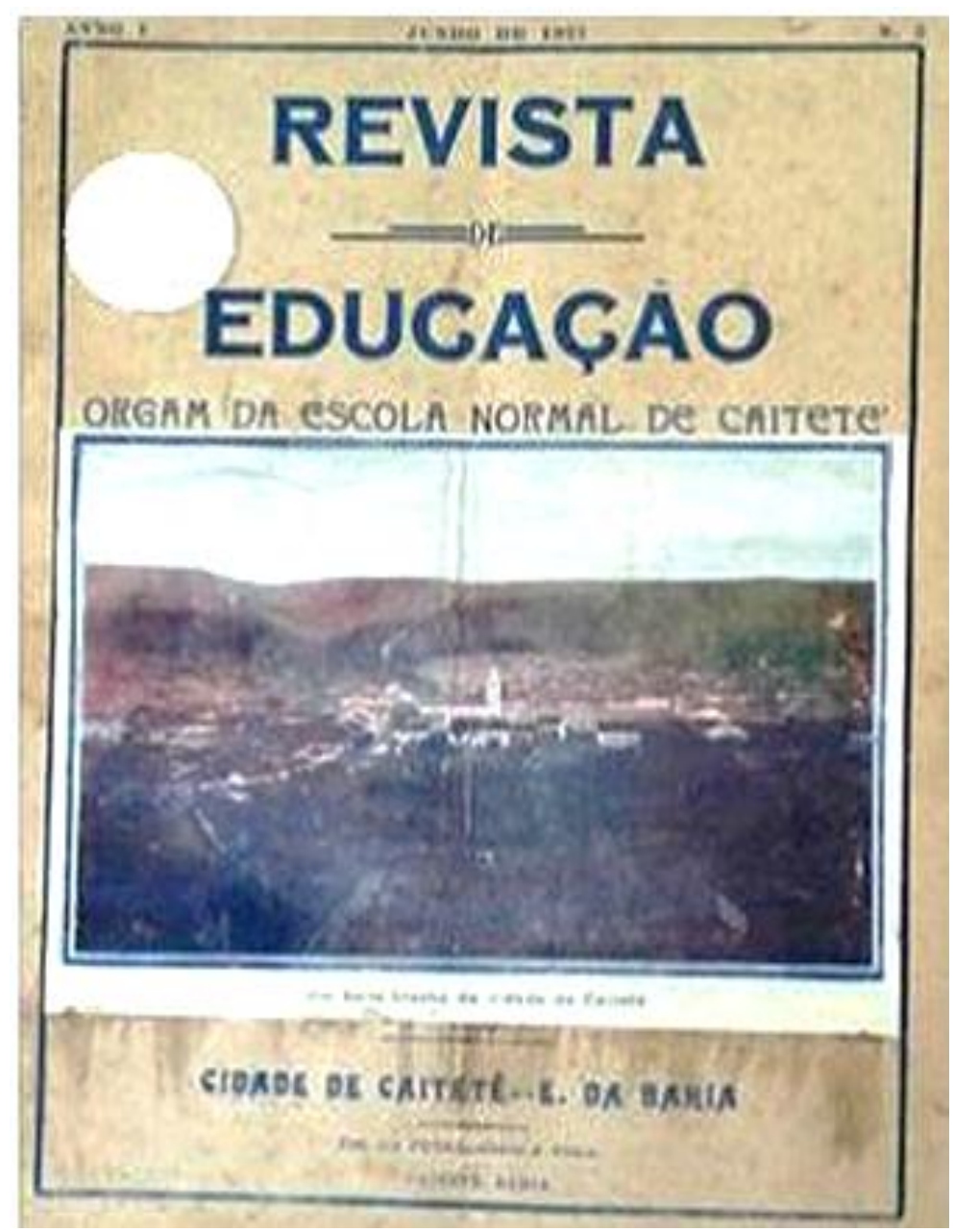

Fonte: Revista de Educação, 1927

O artigo versou sobre a relação dos trabalhos das duas mãos e o ensino do Desenho. Também suas aproximações, treinos, exercícios e outras intersecções que possibilitaram a compreensão e relevância do Desenho no contexto educacional. Segundo os autores do artigo, a Educação Ambidexta:

[...] tem tido, em nossa Escola Normal, logar de destaque. Desde o Jardim de Infancia até o Curso Normal, aprendizagem de trabalhos manuaes e de desenho tem sido feita com as duas mãos, afim de conseguirmos o desapparecimento do privilegio da mão direita[...] (REVISTA DE EDUCAÇÃO, 1927, p. 90).

63“[...] Prática de trabalhar com as duas mãos”. Revista de Educação, 1927, p.91 ISSN 2526-2882

$$
* 156 *
$$


Exercícios bimanuais, segundo o artigo, possibilitavam o desenvolvimento dos centros físicos inferiores e superiores, principalmente nos alunos que apresentavam anomalias físicas. Somado a isso, ressaltaram que "além dos exercícios da mão esquerda, os alumnos praticam também a arte de representar os objectos, desenhando-os com algum desembaraço, manejando o lápis na sinistra com a mesma segurança e destreza da mão direita (REVISTA DE EDUCAÇÃO, 1927, p.90).

\section{Mas qual é sua relação com o Desenho?}

A educação ambidextra entre nós, começa, no Jardim de Infancia, pelos traços elementares das representações graphicas, pelo exercicio da apprehensão de objectos com a mão esquerda. [...] os alumnos traçam livremente linhas curvas, rectas, mixtas, combinandoas na representação dos objectos simples, ora com a mão esquerda, ora com a mão direita, [...] Traçam figuras geométricas com as duas mãos ao mesmo tempo e com os mesmos movimentos (REVISTA DE EDUCAÇÃO, 1927, p.90).

Verifica-se nesse fragmento uma provável interlocução da Ambidextria com o ensino do Desenho, visto que nos exercícios propostos pelos primeiros, utilizavam-se a representação de objetos simples como: animais (figura 2), flores (figuras 3 e 4), frutas (figura 5), símbolos nacionais (figura 6) e o desenho de uma casa (figura 7)

Figura 2: Ambidextria- Desenhos de Animais

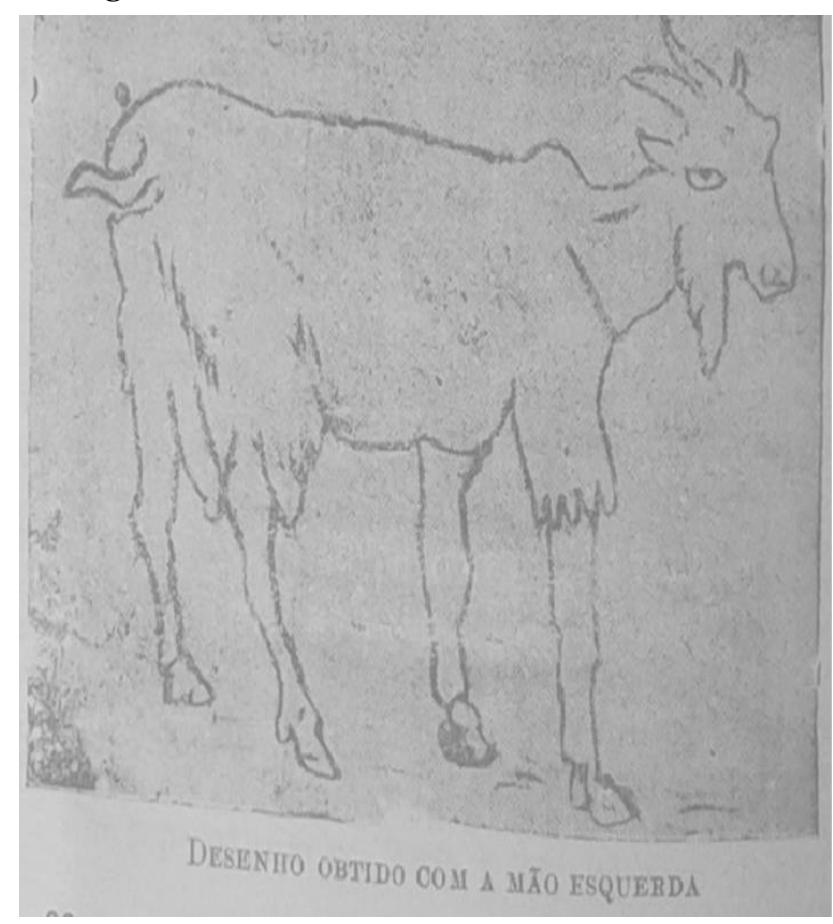

Fonte: Revista de Educação, Jun, 1927, p. 90

ISSN 2526-2882 
Figura 3: Ambidextria- Desenhos de Flores

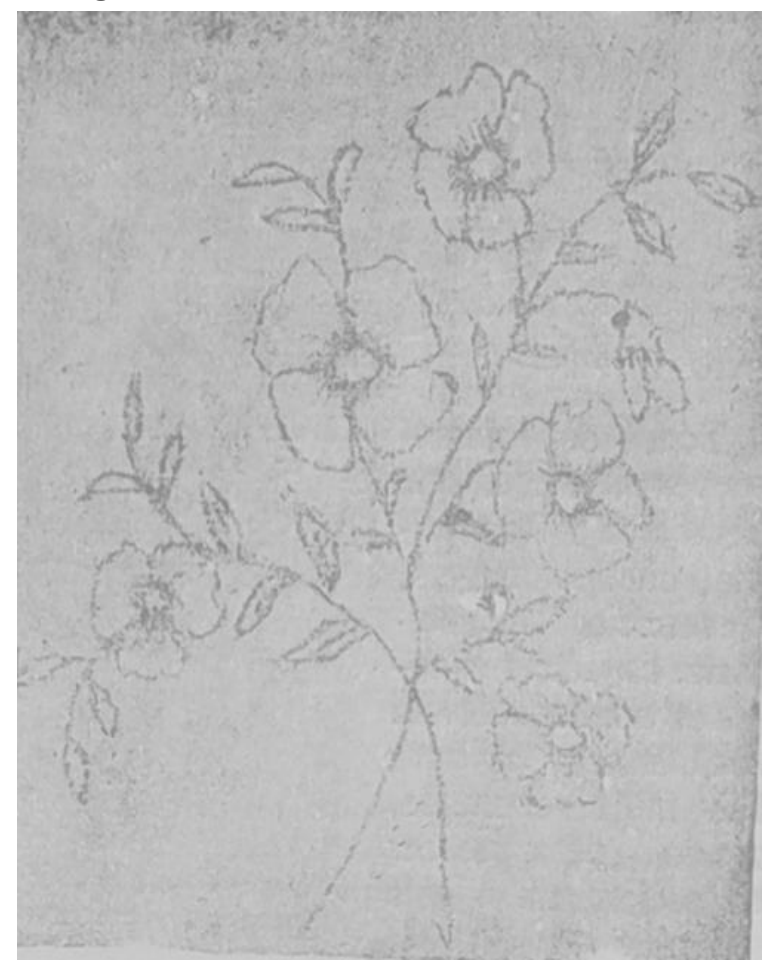

Fonte: Revista de Educação, junho, 1927, p. 91

Figura 4: Ambidextria- Desenhos de Flores

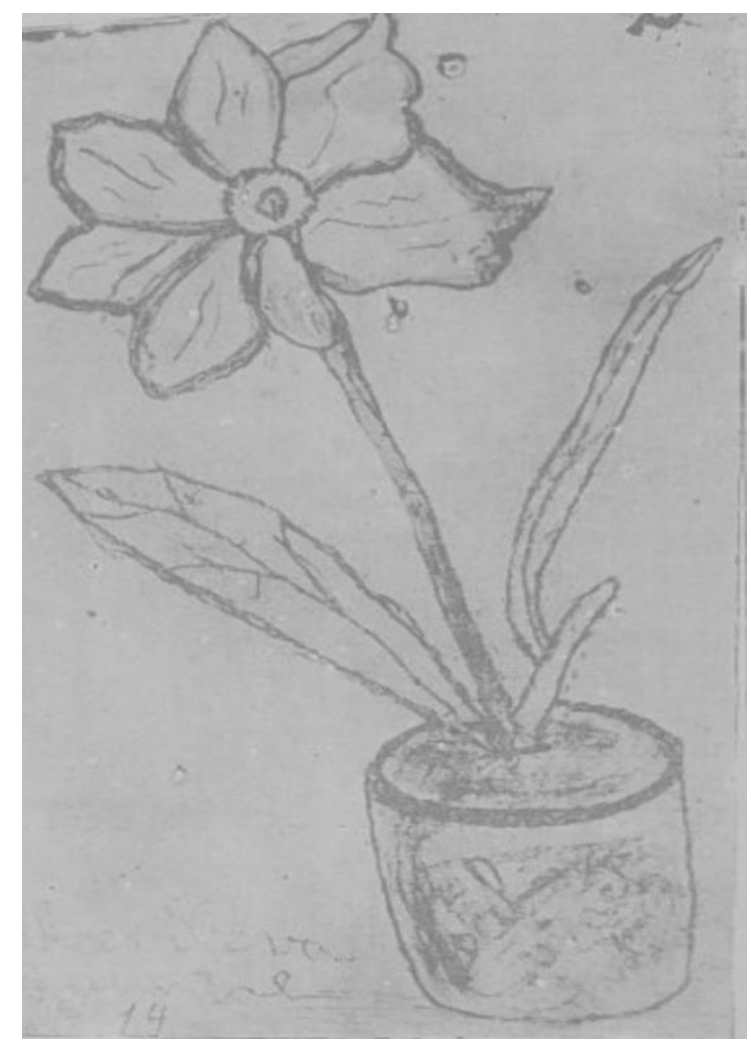

Fonte: Revista de Educação, junho, 1927, p. 92

ISSN 2526-2882

$* * 158 \%$ 
Figura 5: Ambidextria-Desenhos de Frutas

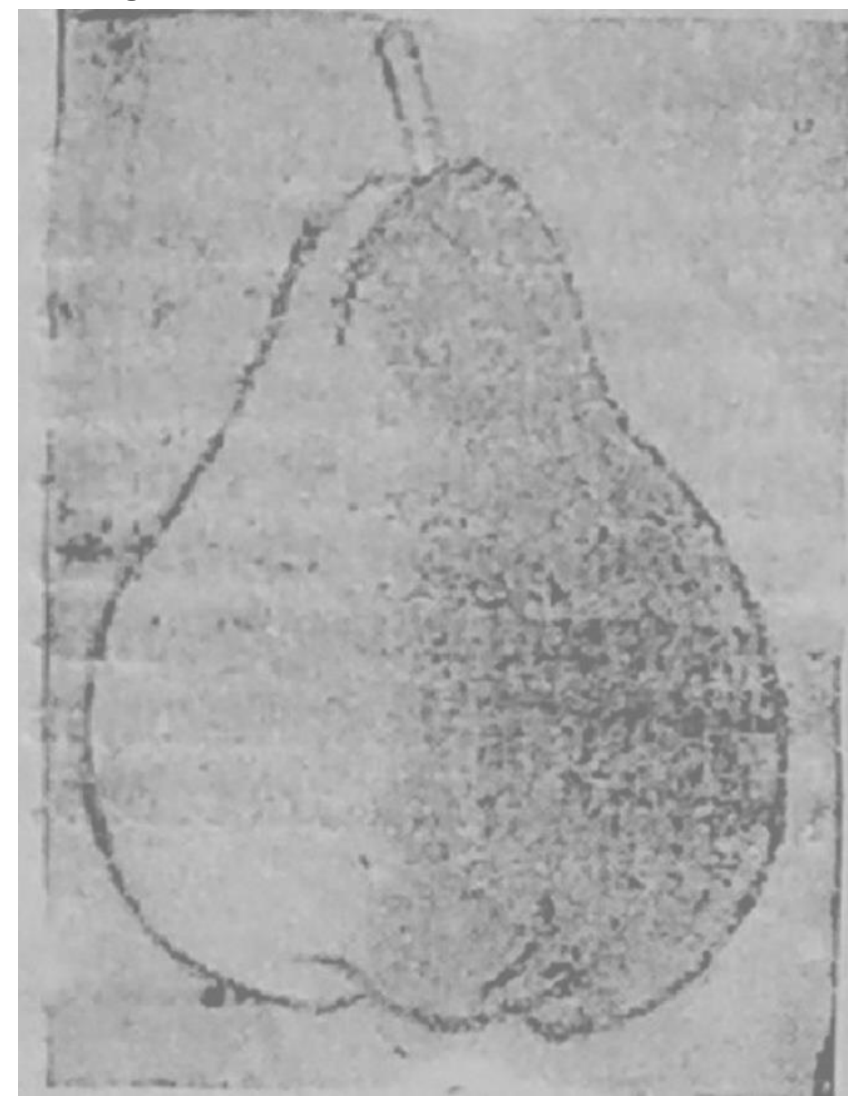

Fonte: Revista de Educação, junho, 1927, p. 91

Figura 6: Ambidextria - Desenhos de Símbolos Nacionais

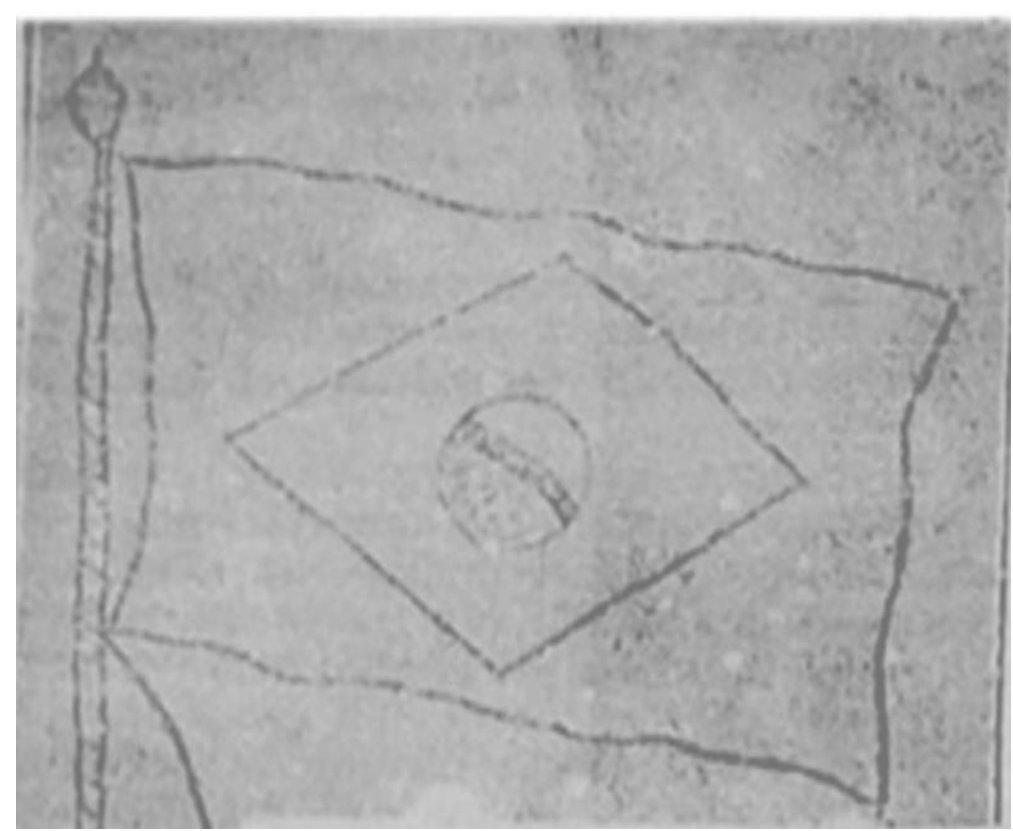

Fonte: Revista de Educação, junho, 1927, p. 91

ISSN 2526-2882

$* 159 \%$ 
Figura 7: Ambidextria- Desenho de uma Casa

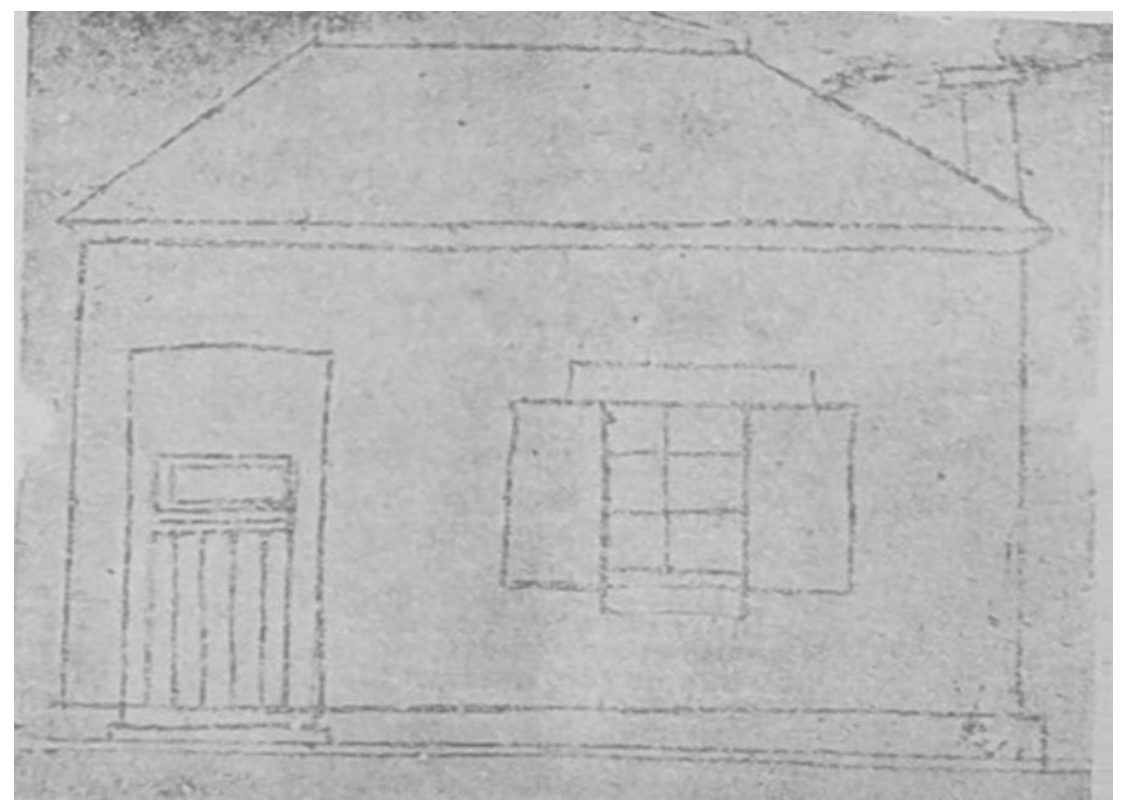

Fonte: Revista de Educação, junho, 1927, p. 91

A citação ${ }^{64}$ também nos impulsiona a supor que para o desenvolvimento da Ambidextria, seria necessário um diálogo permanente entre o ensino do Desenho e a Matemática (Geometria), como os próprios autores alegaram primeiramente que: "A educação ambidextra entre nós, começa, no Jardim de Infancia, pelos traços elementares das representações graphicas [...]”(REVISTA DE EDUCAÇÃO, 1927, p.90). E segundo que: “[...] os alumnos traçam livremente linhas curvas, rectas, mixtas, combinando-as na representação dos objectos simples [...]” (REVISTA DE EDUCAÇÃO, 1927, p.90).

Para subsidiar nossas argumentações e hipótese em torno de um provável diálogo entre a Ambidextria, Desenho e Matemática, citamos Valente (2015), quando elencou sobre os saberes elementares matemáticos, assim descritos:

[...] Como se processam os movimentos e as dinâmicas de constituição dos saberes presentes nos primeiros anos escolares, em particular, da matemática? [...] Onde está presente a matemática nos anos iniciais escolares? Considerando as diversas rubricas do ensino primário, foi possível identificar que os saberes elementares matemáticos integram matérias como: desenho, aritmética, geometria, formas, trabalhos manuais, etc (VALENTE, 2015, p. 197).

Mesmo tendo identificado nesse artigo da Revista de Educação (Junho-1927), algumas características pertencentes à Ambidextria e supostamente sua interlocução com o

${ }^{64}$ Estamos nos referindo a citação apresentada na página 9. 
Desenho e/ou Matemática, não podemos afirmar, se de fato essas proposições ambidextricas foram aplicadas no ensino baiano na década de 1920, ao menos pode contribuir nas investigações futuras sobre a relação da Ambidextria com os vários ramos do Saber Matemático.

Um aspecto que merece destaque refere-se aos valores atribuídos ao Desenho infantil, principalmente quanto ao fortalecimento da espontaneidade, Psicologia, mentalidade e associação com outras disciplinas, assim defendido:

Sabemos que o Desenho Infantil tem uma analogia artistica bem caracterizada com o desenho das épocas antigas, da arte prehistorica, e que a manifestação das ideas dos meninos, por meio da <representação do aspecto visual de um objecto $>$, recebe a actuação de circumstancia exteriores que influem no chamado modelo interno. Temos observado que os alumnos, cujo treino da ambidextria é feito pelo desenho, não soffrem grandes perturbações na sua mentalidade momentânea e na marcha evolutiva da espontaneidade. $\mathrm{O}$ desenhoé uma actividade de applicação tão extensa,[...]que pode associar-se a quase todas as disciplinas.Para a ambidextria, para a pratica de trabalhar com as duas mãos, não conhecemos melhor exercicio que o de desenhar, seja no quadro negro, seja na lousa, seja no papel .A escripta não é um exercicio que desperta tanto os centros emotivos e de interesses, como é o desenho[...](REVISTA DE EDUCAÇÃO, 1927, p.91).

Outro Exemplar catalogado, diz respeito à publicação da Revista de Educação-Orgam da Escola Normal de Caetité, ano I, Agosto de 1927(figura 8), onde identificamos um artigo intitulado “O Segredo do Desenho", sob a responsabilidade de Maria Constança P. Cardoso65.

Figura 8: Capa da Revista de Educação, agosto, 1927

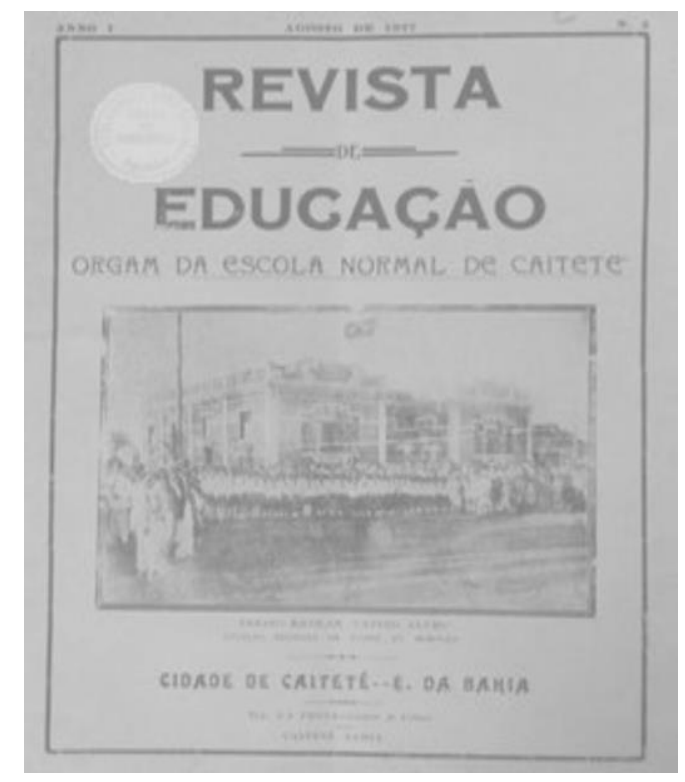

Fonte: Revista de Educação, agosto, 1927

${ }^{65}$ Não localizamos informações detalhadas sobre a autora. ISSN 2526-2882 
Tratou-se de um artigo breve, onde foi ressaltou a importância do Desenho e suas relações com a Anatomia Humana. Vejamos alguns pontos que consideramos pertinentes.

Foi aludido por Cardoso 66 (1927) que o Desenho se tratava de:

[...] um elemento de educação geral, ao mesmo tempo que uma acquisiçãopratica, decisiva, de uma utilidade directa em todas as profissões. Esta arte contribue de um lado para a educação geral, exercendo a precisão do golpe de vista, formando a educação esthetica; de outro lado, sendo o principio básico de todo ensino profissional (CARDOSO, 1927, p. 137).

As proposições levantadas por Cardoso (1927) coadunam com a perspectiva da relevância da Cultura Escolar teorizada por Julia (2001), assim descrita:

[...] poder-se-ia descrever a cultura escolar como um conjunto de normas que definem conhecimentos a ensinar e condutas a inculcar, e um conjunto de práticas que permitem a transmissão desses conhecimentos e a incorporação desses comportamentos; normas e práticas coordenadas a finalidades que podem variar segundo as épocas (finalidades religiosas, sociopolíticas ou simplesmente de socialização) [...] (JULIA, 2001, p. 10-11).

Somado a isso, para autora o Desenho estaria atrelado a duas vertentes: a primeira ligada Educação Generalista, com enfoque no aspecto prático e estético e por outro lado sendo princípio básico para o Ensino Profissional.

E nesse cenário, estudos de Nascimento e Rubio (2014), apontaram que:

No início do século XX o ensino de arte (Desenho) se apresenta como preparação técnica para o trabalho e valoriza o traço, os contornos, e a repetição, Desenho de ornatos, cópias e Desenhos geométricos, visavam a vida profissional para trabalharem em fábricas e com serviços Artesanais (NASCIMENTO; RUBIO, 2014, p.7).

Continuando suas ponderações sobre a relação do Desenho com a Arte, Cardoso (1927) salientou:

[...] para que os alumnos possam se utilizar dos principios básicos desta arte, torna-se mister, que esses principios lhes sejam mostrados e definidos.Se ignorarmos a fórma, a posição dos ossos, de que è composta, por exemplo, a mão humana, certamente, muito difícil tornar-se-a o seu sombreamento. E de que necessitaremos, para destribuirmos com precisão o jogo de sombra e luz? Sem duvida alguma, de um estudo sobre Anatomia. (CARDOSO, 1927, p. 137).

${ }^{66}$ Estamos nos referindo à Maria Constança P Cardoso, autora do artigo "O segredo do Desenho", publicado na Revista de Educação-Agosto de 1927. 
Verifica-se que para a autora, os princípios da forma e posição provavelmente exerciam forte influência sobre o Desenho. E para reforçar o estudo da anatomia, a mesma afirmou que:

Miguel Angelo, o afamado pintor italiano, um dos maiores artistas conhecidos, que sempre distingui-se pela originalidade de suas concepções, pela diversidade e caracter grandioso de suas obras, considerava a <Anatomia>, como o fundamento do Desenho (CARDOSO,1927, p. 137).

O terceiro periódico educacional que catalogamos e analisamos foi uma publicação de Fevereiro (1928) da Revista de Educação (figura 9), a qual trazia um artigo intitulado "O Ensino do Desenho na Escola Primária”, de autoria dos redatores ${ }^{67}$ da referida revista.

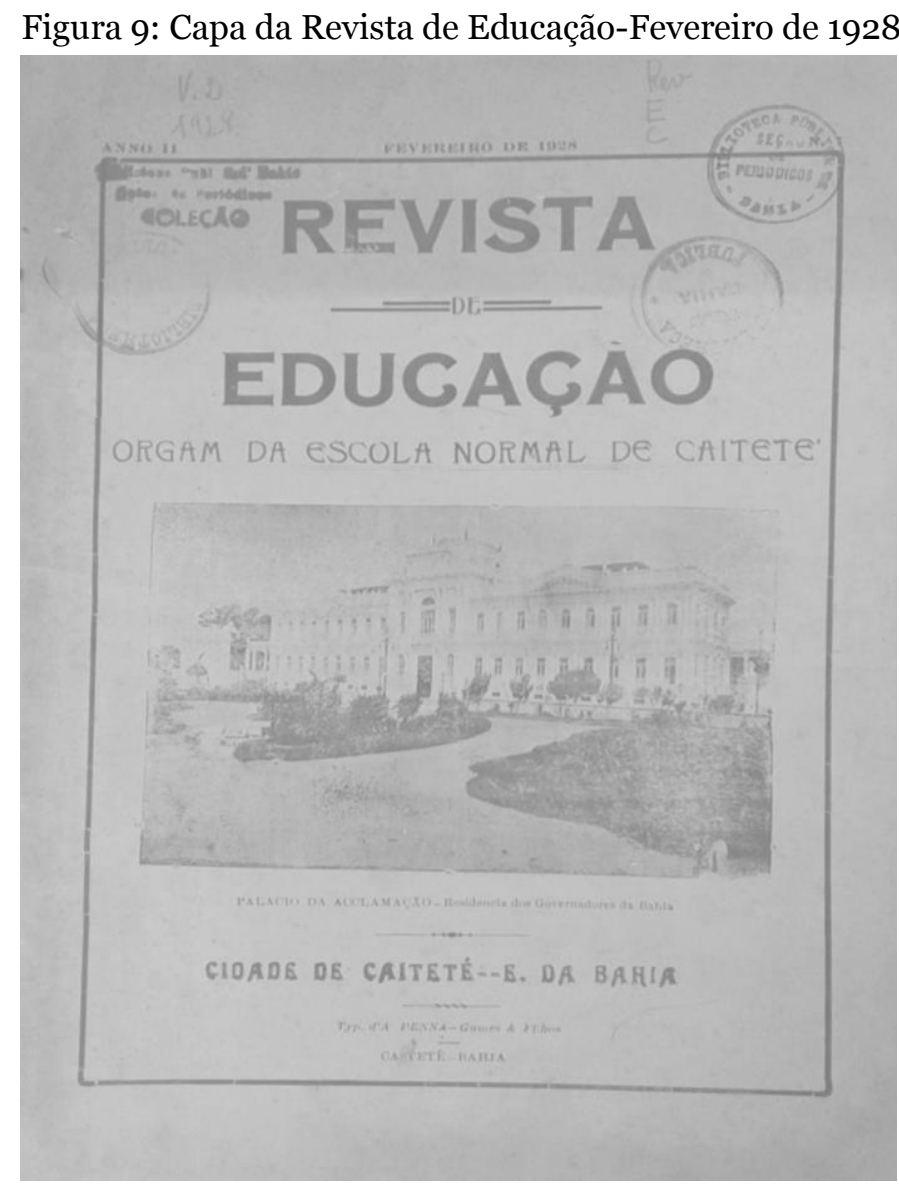

Fonte: Revista de Educação, fevereiro, 1928

Segundo os autores, o ensino do Desenho tinha um lugar de destaque na técnica educativa, isso devido sua finalidade principal, assim expressa:

${ }^{67}$ São eles: Professores Alfredo José da Silva e Salvador da Rocha Passos, Professoras Dulce da Silva Araujo e Helena Lima. 
O fim principal do ensino do desenho é, talvez, proporcionar o desenvolvimento da faculdade de observação da criança, e, tambem, facilitar a traducção das suas concepções, representações por meio de traços dos objectos que já conhecem, etc. O desenho é um meio de expressão; é u'a manifestação da actividade humana (REVISTA DE EDUCAÇÃO, 1928, p. 243).

Por essa passagem, os autores pontuaram que o ensino do Desenho proporcionava o desenvolvimento da faculdade de observação das crianças, favorecendo a interpretação das concepções e as representações dos objetos. Também salientaram que o Desenho era um meio de expressão e manifestação da atividade humana.

Apesar de toda essa relevância do Desenho na educação, os autores afirmaram que: "Não é facil ensinar desenho ás crianças, principalmente na segunda infancia, quando a sua actividade creadora começa a se desenvolver e adquire cada vez mais a feição de ordem” (REVISTA DE EDUCAÇÃO, 1928, p.243).

Na continuidade do artigo, os idealizadores expuseram mais uma vez a importância do Desenho para as crianças, assim descrito:

Por meio do desenho a excitação dos centros mentaes se faz com regular predominancia, a faculdade de escolher e a perspicacia sobresaem na trama das impressões externas; as forças associativas se conjugam, as crianças se familiarizam com os objetos e com as formas geometricas, definindo-os pelos traços e no rigor das expressões (REVISTA DE EDUCAÇÃO, 1928, p. 243).

Esse fragmento nos revelou outros benefícios que o ensino do Desenho poderia proporcionar as crianças, principalmente no que se refere ao desenvolvimento dos centros metais, da capacidade de escolha, das perspicácias com as questões ligadas as impressões externas e o favorecimento do reconhecimento de objetos e formas geométricas.

Outro aspecto que nos chamou atenção no artigo foi à veiculação do Desenho infantil com as fases do desenvolvimento mental das crianças, que de acordo com os autores:

Pelo Desenho infantil conhecemos as varias phases do desenvolvimento mental das creanças. De accordo com Kerschenteiner ${ }^{68}$, a primeira phase é a do <schema , porque o menino só desenha as qualidades ideaes. Mas nesta phase a criança vae modificando grativamente os detalhes, as qualidades, formas vão sendo representadas pela continuidade das linhas até a penetração total na phase da $<$ silhueta $>$. A mais importante phase é a do $<$ sentimento $>$, quando a criança tem comprehensão mais ou menos firme da forma e dos detalhes. Cultivar na criança o sentimento da expressão por meio do graphico, elevar a imaginação á conquista de syntheses de detalhes, coordenar as observações, etc [...] (REVISTA DE EDUCAÇÃO, 1928, P. 243).

\footnotetext{
${ }^{68}$ Filósofo e educador alemão, nascido em Munique, onde também morreu. Ele é um dos mestres do movimento da "nova escola" e uma das figuras mais eminentes da pedagogia alemã em nosso século. Disponível em: http://www.mcnbiografias.com/app-bio/do/show?key=kerschensteiner-georg-michael. Acesso em 26/12/2017. ISSN 2526-2882

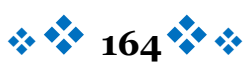


Por esse fragmento, os autores defenderam que o método do pedagogo alemão Kerschensteiner no que se refere às fases do desenvolvimento mental das crianças, possuíam uma estreita relação com o ensino do Desenho infantil e que se estabeleciam mediantes fases as quais seriam: Do esquema, silueta e sentimento. A primeira fase (schema) estaria relacionada com as qualidades ideais e o avanço gradativo dos detalhes. A segunda fase (silhueta), sendo representada pela continuidade das linhas e a terceira (sentimento), indicando que a criança compreendeu mais ou menos a forma e os detalhes. Por fim, ressaltaram que de acordo com a pedagógica moderna o trabalho do professor favorecia a recolha dos elementos para as experimentações da inteligência infantil.

Ao finalizar o referido artigo, os autores expressaram a relevância do Desenho com os demais conhecimentos e o papel dos professores nesse processo de aproximação.

As relações que o desenho tem com os demais conhecimentos e o importante papel que elle representa na educação, merecem o carinho dos professores e um estudo cuidadoso das vantagens que advêm ao educando. No desenho o menino pode exaggerar as expressões, augmentar ou diminuir os detalhes, mas não pode mentir, rigosamente, ás imagens que se representam na sua téla mental (REVISTA DE EDUCAÇÃO, 1928, p.243).

Esse fragmento ainda aponta que o ensino do Desenho poderia ser usado como meio de divulgação das expressões e detalhes artísticos, fortalecendo sobremaneira a "tela mental" do educando.

\section{Caminhos para pesquisa}

Ao analisarmos algumas publicações das Revistas de Educação-Orgam da Escola Normal de Caetité em 1927 e 1928, identificamos algumas argumentações suscitadas por determinados educadores da época que discorriam sobre a concepção e relevância do Desenho na década de 1920.

Tais educadores versaram sobre a proximidade do ensino de Desenho com a Anatomia Humana, Ambidextria, Espontaneidade, Psicologia, Matemática (Geometria), Mentalidade e Expressões Artísticas etc.

Vimos também que o ensino do Desenho poderia estar atrelado a duas vertentes: a primeira em relação ao Ensino Geral e a segunda com o Ensino Profissional. Somado a isso, verificamos que o ensino do Desenho seria capaz de proporcionar o desenvolvimento da faculdade de observação das crianças, favorecendo a interpretação das concepções e as representações dos objetos. Também salientaram que o Desenho era um meio de expressão e manifestação da atividade humana. 
Enfim, muitos atributos foram designados para o Desenho, segundo os artigos veiculados na Revista de Educação-Orgam da Escola Normal de Caetité, contudo, é necessário advertir que em hipótese alguma estamos afirmando que essas ponderações promovidas por tais educadores, tenham influenciado o ensino do Desenho no Estado da Bahia, contudo nos apontam algumas discussões que giravam em torno dessa disciplina.

As investigações as quais iniciamos em determinados artigos veiculados nas referidas revistas, nos apontaram que o ensino do Desenho na década de 1920 na Bahia, poderia favorecer a faculdade de observação da criança e a representação dos aspectos visuais dos objetos.

É relevante salientar que nesse primeiro momento estamos investigando as principais argumentações e características do Desenho apresentadas nos periódicos educacionais supracitados, e posteriormente faremos uma análise criteriosa sobre sua relação ou não com a Matemática.

Por fim, almejamos que na continuidade das nossas investigações historiográficas, possamos colaborar na seguinte problematização: Como se estabeleceu o ensino de Desenho e sua relação com a Matemática na década de 1920 no Estado da Bahia?

\section{Referências}

BAHIA. Mensagem apresentada pelo Exmo. Sr. Dr. Francisco Marques de Góes Calmon, governador do Estado da Bahia á Assembléia Geral Legislativa, por ocasião da $2^{\text {a }}$ reunião ordinária da $18^{\text {a }}$ legislatura. Salvador: Diário da Assembléia Geral, 1926. Disponível em: http://memoria.bn.br/DocReader/721050/708. Acesso em 10/06/2017

. Lei n. 1.846, de 14 de agosto de 1925. Leis do Estado da Bahia dos anos de 1924 e 1925. Bahia Imprensa Oficial do Estado, 1925b. Disponível em: https://repositorio.ufsc.br/handle/123456789/134871. Acesso em: 21/05/2017.

BASTOS, M. H. C. A imprensa periódica educacional no Brasil: de 1808 a 1944. In: CATANI, Denice Barbara; BASTOS, Maria Helena Câmara (Orgs.). Educação em Revista: a imprensa periódica e a História da Educação. São Paulo: Escrituras, 1997. p. 173- 187.

BERTI, N. M. O Ensino De Matemática no Brasil: Aspectos para uma compreensão histórica. In: VI Jornada Nacional do HISTEDBR, 2005, Ponta Grossa - PR. Reconstrução Histórica das instituições escolares no Brasil. Ponta Grossa - PR: UEPG, 2005.

BOMENY, H. Os intelectuais da educação. 2ed. Rio de Janeiro: Jorge Zahar, 2003.

CATANI, D. B. A imprensa periódica educacional: as revistas de ensino e o estudo do campo educacional. Revista Educação e Filosofia v.10, nº20, p. 115-130, jul.- dez. 1996. 
CERRI, L. F. Ensino de História e concepções historiográficas. Espaço Plural (Unioeste), v. X, p. 149-154, 2009.

CHERVEL, A. (1990). História das disciplinas escolares: reflexões sobre um campo de pesquisa. Teoria \& Educação, 2, 177-229

COSTA, David Antônio; VALENTE, Wagner Rodrigues. O repositório de conteúdo digital nas pesquisas de história da educação matemática. Rev Iberoam. Patrim. HistóricoEducativo, Campinas (SP), v.1, n.1, p.96-110, jul./dez.2015

D'ESQUIVEL, M. O.; SANT'ANA, C. C. DO DESENHO À GEOMETRIA: saberes geométricos na escola primária da Bahia. Revista Brasileira de História da Educação Matemática, v. 2, p.174-197, 2016.

DIAS, A. L. M. Tendências e Perspectivas Historiográficas e Novos Desafios na História da Matemática e da Educação Matemática. Educ.Pesq. São Paulo, v.14, n.3, p.301-321, 2012.

HANAUER, F. Riscos e Rabiscos. O desenho na educação infantil. Revista de Educação do Ideau. Vol. 6, $\mathrm{N}^{\mathrm{o}}$ 13, Janeiro - Julho, 2011.

JULIA, D. A cultura escolar como objeto histórico. Revista Brasileira de História da Educação, Campinas, n. 1, p. 9-43, 2001.

LEME da Silva, M. C.; VALENTE, W. R. A geometria dos grupos escolares: Matemática e Pedagogia na produção de um saber escolar. Cadernos de História da Educação, vol.11, p. 559-571, 2012

LUZ, José. Augusto. R.A Salvação pelo Ensino Primário: Bahia (1924-1928). $1^{\mathrm{a}}$. Ed. Feira de Santana: UEFS Editora, 2013.v.500.274p.

NASCIMENTO, D. S.; RUBIO, J. de A. S. Revista Eletrônica Saberes da Educação Volume $5, \mathrm{n}^{\mathrm{O}} 1,2014$.

SANT'ANA, C. C; SANTANA, I. P. (2015). As revistas pedagógicas no estado da Bahia. XII Seminário Temático Saberes Elementares Matemáticos do Ensino Primário (1890 - 1971): o que dizem as revistas pedagógicas? Disponível em: https/www2.td.utfpr.edu.br/seminario_tematico/artigos/129.pdf. Acesso em 25/06/2017.

AMARAL, R. dos S.; SANTANA, I. P.; SANT'ANA, C. de C. LIVROS DIDÁTICOS E MANUAIS PEDAGÓGICOS: o ensino de Matemática no Curso Primário dos anos de 1960. Interfaces Científicas - Educação, 28 fev. 2015. V. 3, n. 2, p. 77-86.

VALENTE, W. R. A Educação Matemática e os Estudos Históricos Comparativos: de sua legitimidade à sua viabilidade. In: Anais do XIII CIAEM-IACME, Recife, Brasil, 2011.

ISSN 2526-2882

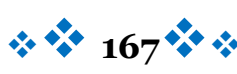




\section{Biografia Resumida}

Emanuel Silva Santos: Professor do Colégio Militar do Município de Anagé-BA. Mestre em Educação em Ciências e Matemática (UESB-BA). Especialista em Educação, Cultura e Memória (UESB-BA). Integrante do Grupo de Pesquisa em Educação Matemática - GEEM. Desenvolve pesquisas em História do Ensino da Matemática.

Link Lattes: http://Link Lattes.cnpq.br/2774790985518974

e-mail: xiiitos@gmail.com

Claudinei de Camargo Sant 'Ana: Possui graduação em Licenciatura em Matemática pela Pontifícia Universidade Católica de Campinas, PUC-Campinas (1988), em Pedagogia pela Faculdade de Ciências e Letras Plínio Augusto do Amaral, FCLPAA (1990), e especialista em Informática em Educação pela Universidade Federal de Lavras, UFLA (2007), mestrado em Engenharia Mecânica pela Universidade Estadual de Campinas, Unicamp (1995), doutorado em Educação pela Universidade Estadual de Campinas, Unicamp (2008), em 2010 realizou estágio de pós-doutoramento na Universidade Estadual Paulista Júlio de Mesquita Filho, UNESP/Rio Claro; em 2016 realizou estágio de pós-doutoramento na Université de Limoges Faculté des Sciences et Techniques, Limoges/França. Lecionou em instituições de ensino fundamental, médio e superior. Editor da Revista Eletrônica "Com a Palavra, o Professor", e atualmente é professor Titular da Universidade Estadual do Sudoeste da Bahia, trabalha nos cursos de Matemática, Pedagogia e orienta dissertações de Mestrado no Programa de Pós-Graduação Educação Científica e Formação de Professores (PPG-ECFP), no Programa de Pós-Graduação em Ensino (PPGEn). Atualmente é membro da comissão científica da Sociedade Brasileira de Educação Matemática na Bahia, SBEM/Ba. Tem experiência na área de Educação, com ênfase em Educação Matemática, Educação a Distância; atuando principalmente nos seguintes 
temas: Aprendizagem da Matemática, História do Ensino da Matemática, Tecnologia Informática e Formação de Professores. Link Lattes: http://Link Lattes.cnpq.br/2970320445020239 e-mail: claudinei@ccsantana.com 